\title{
Analysis of the Viscoelastic Properties OF POLYMERIC MATERIALS USED FOR 3D PRINTING
}

\author{
Obucina, M., DZAFERovic, E., IBRUlJ, J., CEKIC, A., \\ KuZMAN, K. M., KARIZ, M. \& SERNEK, M.
}

Abstract: This paper presents an analysis of the viscoelastic properties of polymeric materials obtained by $3 D$ printing from $A B S$ plastic. The review summarizes the principle of $3 D$ printing as well as the experimental determination (measurement) of the relaxation module of polymeric materials. Below is a model for analysing material characteristics using the numerical method. The numerical method used in this paper is a finite volume method, and the results obtained by this method are compared and presented in several diagrams.

Key words: $3 D$ printing, ABS plastic, viscoelastic properties, numerical analysis
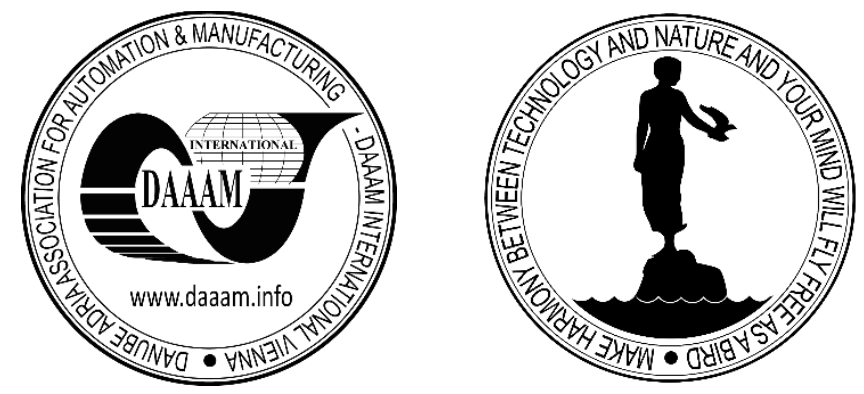

Authors' data: Univ. Prof. Dipl. Ing. Of Mechanical Engineering Dr. Obucina, M[urco]*; Dr. Dzaferovic E[jub]*; Dr. Ibrulj J[usuf]*; Dr. Cekic A[hmet]*; Dr. Kuzman, K. M[anja]**; Dr. Kariz, M[irko]**; Dr. Sernek M[ilan]**, *Faculty of Mechanical Engineering in Sarajevo, Bosnia and Herzegovina, **Biotechnical faculty, Department of wood science and technology, Ljubljana, Slovenia, obucina@mef.unsa.ba,_dzaferovic@mef.unsa.ba, cekic@mef.unsa.ba, manja.kuzman@bf.uni-lj.si, j_ibrulj@yahoo.com, milan.sernek@bf.uni-lj.si mirko.kariz@bf.uni-lj.si,

This Publication has to be referred as: Obucina, M[urco]; Dzaferovic, E[jub]; Ibrulj, J[usuf]; Cekic, A[hmet]; Kuzman, K. M[anja]; Kariz, M[irko] \& Sernek, M[ilan] (2018). Analysis of the Viscoelastic Properties of Polymeric Materials used for 3D Printing, Chapter 08 in DAAAM International Scientific Book 2018, pp.083-096, B. Katalinic (Ed.), Published by DAAAM International, ISBN 978-3-902734-19-8, ISSN 1726-9687, Vienna, Austria

DOI: $10.2507 /$ daaam.scibook.2018.08 
Obucina, M.; Dzaferovic, E.; Ibrulj, J.; Cekic, A.; Kuzman, K. M.; Kariz, M. \& Ser...

\section{Introduction}

Three-dimensional printing (3D printing) is a method of rapid prototyping that "prints" objects layer by layer based on patented 3D technology directly from 3D CAD programs and creates physical objects from digital models. Three-dimensional printing gives engineers the opportunity to clearly understand the process of design, the possibility of highlighting various parameters, the possibility of easy and early detection of possible errors and their quick and efficient correction. In order to meet product demands, different 3D printing methods are used such as fused deposition modelling (FDM), selective laser melting (SLM), stereolithography (SLA), digital light processing (DLP), selective laser sintering (SLS), selective laser melting (SLM), and electron beam melting (EBM) (Berman, 2012).

The main difference between the available 3D printing techniques are the materials, the way in which the layers are obtained and the properties of the printed object. Some of the techniques melt the materials to form it in layers, while others harden the liquid polymers in different ways (heat, laser beam, UV light), and others cut the thin layers of the material and then bond them together. The main principle of $3 \mathrm{D}$ printing is building the model layer by layer. This allows building shapes that are impossible to create with conventional cutting technologies without making moulds or special tools. Using these capabilities of a 3D printer, the prototype production time is greatly reduced, and the quality of the model is increased. 3D printers are nowadays using in several areas: architecture, design, informatics, education, machine building, aeronautics, metallurgy, modelling, medicine, bio-modelling, geo-info systems, and molecular chemistry. 3D printers are mini-systems with numerical control (NC) in three axes (x, y, and $\mathrm{z}$ ).

System software first converts a 3D CAD digital model into cross-sections, i.e. thin layers of thickness $0.05-0.4 \mathrm{~mm}$, this is chosen depending on the accuracy to be achieved and the printer/material specifications. When using FDM technique, the object (model) is made in such a way that a polymer (in the form of a filament) is melted in the extruder head and deposited in thin layers starting with the lowest layer and building the model upward. By selecting the type of material, users can create items of different properties, depending on the technical requirements that the model needs to satisfy (strength, elasticity, temperature endurance, etc.). The greater the complexity of the element, the greater the advantage of 3D printing over the conventional production system.

In addition, 3D printing efficiently uses raw materials, leading to a very low or zero level of waste (Cekic, et el. 2017; \& Wimmer et al. 2015). Reducing the amount of waste material is especially important from the aspect of environmental protection. During the process of "layer-by-layer" printing, the material passes through physical and thermal changes concerning its mechanical properties. Using Dynamic Mechanical Analysis (DMA), it can be ascertained that the dynamic properties of the material change depending on the process parameters and how such parameters affect the mechanical properties (Mohamed et. al.; Arivazhagan \& Masood. 2012). This article presents the results of the measurement (experiment) of such characteristics that were subsequently approximated by certain analytical expressions. 
Finally, when a relaxation function and its analytical form were available, it was used in the numerical approach to verify the results obtained from the experiment.

\section{Experimental analysis}

In dynamic mechanical analysis, the stress value periodically varies, usually using the sinusoidal change in the angular frequency applied to the sample (Menard 1999). From the response to the applied mechanical load of the sample, information such as the stiffness of the material can be obtained. The rigidity of the material is determined by the value of the elastic modulus. The deformation obtained from the periodic stress change will also be periodic, but displaced for a given value of the phase angle due to energy dissipation in the form of heat. In dynamic mechanical tests, the stiffness of the material over time is measured. The stiffness of the sample depends on the modulus of elasticity of the material. The elastic modulus is defined as the value of the stress divided by the deformation resulting from the applied force. Young's modulus (elasticity) is the slope of the initial part of the strain-strain curve and is a measure of the material's resistance to deformation. The higher the modulus, the greater is the stiffness of the material (Brown, 2001).

One of the main advantages of DMA is that for each sinusoidal load, the value of the module can be obtained, which enables varying the values of the temperature or frequency to a certain extent. If the experiment is working at $1 \mathrm{~Hz}$, the value of the module for each second can be obtained. Measurements can be done at isothermal temperature or during increasing temperature (temperature sweep), with constant amplitude or with increasing amplitude (amplitude sweep) (Kariz, 2011). In this paper, amplitude sweep at isothermal conditions was used.

The samples for the research were printed from Z-ABS filament (Zortrax, Poland) with a Zortrax M200 3D printer. A nozzle with $0.4 \mathrm{~mm}$ and a filament with $1.75 \mathrm{~mm}$ diameter were used to print samples dimensions $50 \times 12 \times 4 \mathrm{~mm}$ for tests on the rheometer and $80 \times 10 \times 4 \mathrm{~mm}$ for bending tests. The printing nozzle temperature was $275^{\circ} \mathrm{C}$ and printer bed temperature $80^{\circ} \mathrm{C}$. Samples were printed with different layer thicknesses $0.09 \mathrm{~mm}, 0.19 \mathrm{~mm}$, and $0.39 \mathrm{~mm}$.

The samples had the same structure: three outer layers were filled with material, and the internal structure was a mesh structure with square size of $1.25 \mathrm{~mm}$ and a line thickness of $0.4 \mathrm{~mm}$ (Fig. 1).

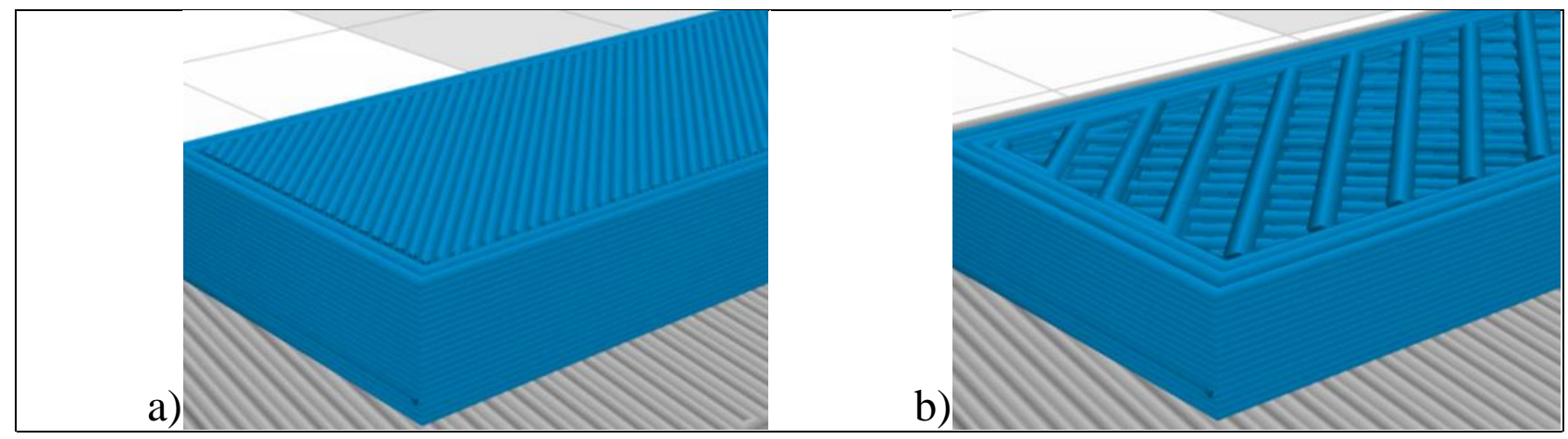

Fig. 1. Printed samples: (a) filled layers in three outer layers; (b) mesh structure inside. 
Obucina, M.; Dzaferovic, E.; Ibrulj, J.; Cekic, A.; Kuzman, K. M.; Kariz, M. \& Ser...

An ARES-G2 TA Instruments rheometer (Fig. 2) was used in the research for dynamical mechanic analysis of the samples. Samples were clamped to a rectangular torsion fixture, and torsional sinusoidal loading of the samples was used.

The test procedure was controlled with a computer and Trios software.Amplitude tests with oscillating amplitude were made at $1 \mathrm{~Hz}$ with increasing strain from $1.0 \times 10-6$ to the end of the linear viscoelastic region of the material, which was determined at sudden change (more than $5 \%$ ) of storage modulus.

The tests were conducted at a constant temperature $30^{\circ} \mathrm{C}$. The storage modulus, loss modulus, and $\tan \delta$ were calculated from measurements of response of the material.

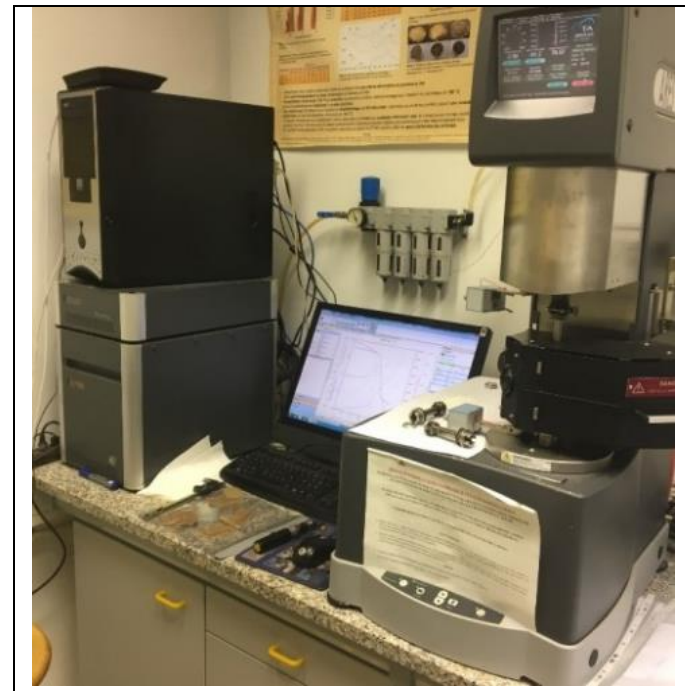

a)

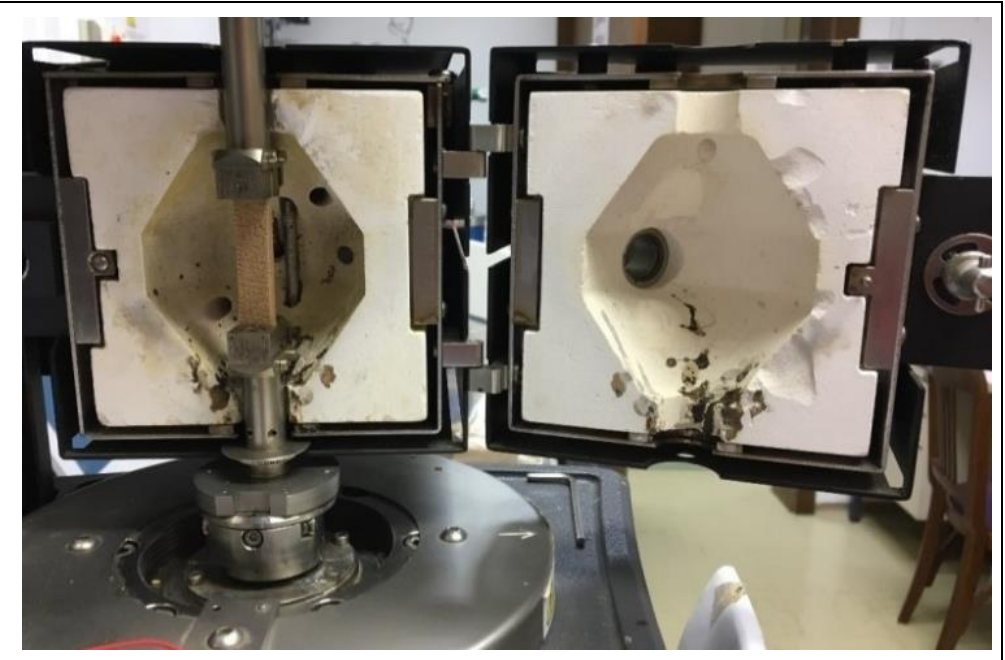

b)

Fig. 2. Dynamical mechanic analysis of the samples: (a) Rheometer ARES-G2, Sample clamped in torsion fixture in controlled temperature chamber.

Oscillatory rheometry is a technique similar to DMA that is used for monitoring the mechanical properties of the material. The material is oscillatorily loaded and the response is measured with different methods.

The response can be elastic (represented with elastic or storage modulus $\left(\mathrm{G}^{\prime}\right)$, viscous (represented with loss modulus $\left(\mathrm{G}^{\prime \prime}\right)$. For real materials, the response is usually a combination of elastic and viscous response.

The Tan $\delta$ is a ratio between the loss module and the storage module, and is sometimes also called a dumping factor. The tensile tests of the samples were made on a ZwickRoel Z005 universal testing machine (Fig. 3) with a constant loading speed of $1 \mathrm{~mm} / \mathrm{min}$. 


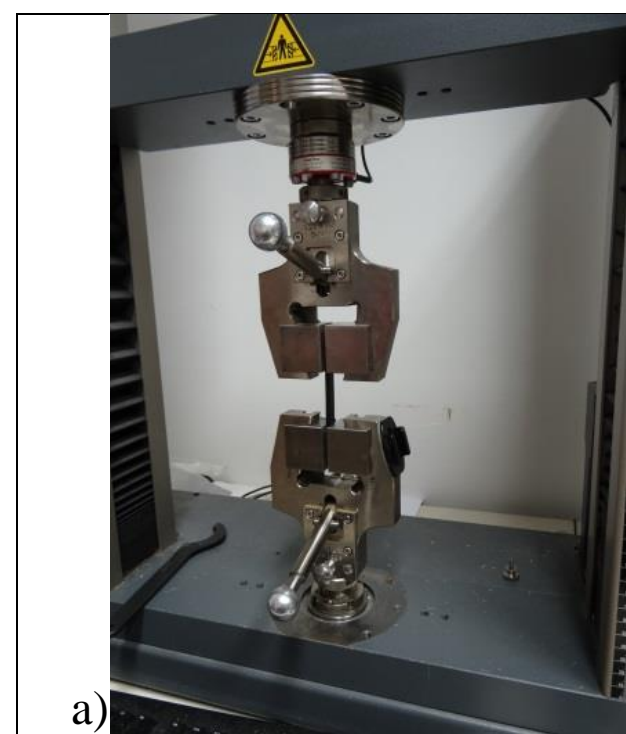

b)

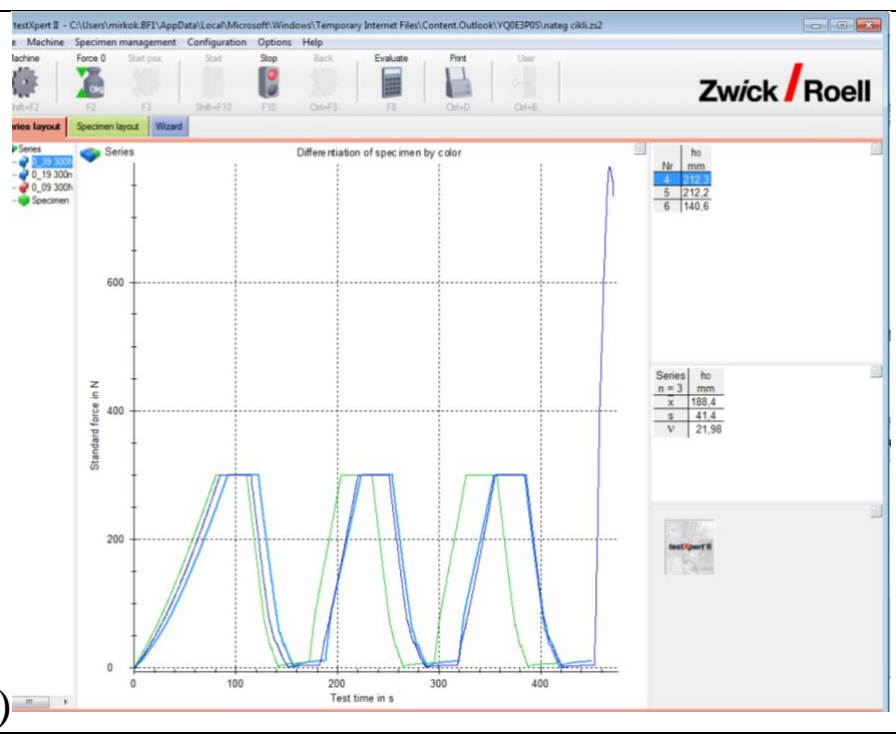

Fig. 3. The tensile tests of samples: (a) Tensile tests on Zwick Roel Z005 universal testing machine, (b) TestXpert software for controlling tensile tests.

\section{Numerical analysis}

The mathematical model consists of energy equations, the equations of the dynamic equilibrium in an integral form, the corresponding constitutive relations, and the initial and boundary conditions in the domain of solution. The basic equations are expressed symbolically in integral form:

$$
\begin{aligned}
& \int_{V} \frac{\partial}{\partial t}\left(\rho c_{q} T\right) \mathrm{d} V=-\int_{S} \mathbf{q} \cdot \mathrm{d} \mathbf{s}+\int_{V} \rho S_{q} \mathrm{~d} V, \\
& \int_{V} \frac{\partial}{\partial t}\left(\rho \frac{\partial \delta \mathbf{u}}{\partial t}\right) \mathrm{d} V=\int_{S} \delta \mathbf{T} \cdot \mathrm{d} \mathbf{s}+\int_{V} \rho \delta \mathbf{f}_{b} \mathrm{~d} V .
\end{aligned}
$$

For isotropic viscoelastic materials, a constitutive relationship that gives a link between stress and deformation, including thermal effects, is represented as follows (Demirdzic et al. 2005; Dzaferovic et al., 2000):

$$
\mathbf{T}(t)=\int_{0}^{t} 2 \eta\left(t^{\prime}-\tau^{\prime}\right) \frac{\delta \mathbf{E}(\tau)}{\delta \tau} \mathrm{d} \tau+\mathbf{I}\left\{\int_{0}^{t}\left[\lambda\left(t^{\prime}-\tau^{\prime}\right) \operatorname{tr}\left(\frac{\delta \mathbf{E}(\tau)}{\delta \tau}\right)-3 K\left(t^{\prime}-\tau^{\prime}\right) \alpha(T) \frac{\delta T(\tau)}{\delta \tau}\right] \mathrm{d} \tau\right\}
$$

Or in incremental form:

$$
\delta \mathbf{T}(t)=2 \eta\left(t^{\prime}-\tau^{\prime}\right) \delta \mathbf{E}(\tau)+\mathbf{I}\left[\lambda\left(t^{\prime}-\tau^{\prime}\right) \operatorname{tr}(\delta \mathbf{E}(\tau))-3 K\left(t^{\prime}-\tau^{\prime}\right) \alpha(T) \delta T(\tau)\right]
$$

Where is $\delta \mathrm{T}(\mathrm{t}), \delta \mathbf{E}(\tau)=1 / 2\left[\operatorname{grad} \delta \mathbf{u}(\tau)+(\operatorname{grad} \delta \mathbf{u}(\tau))^{\mathrm{T}}\right]$, and $\delta \mathbf{u}$, increment of stress, strain and displacement, $q$ - heat flux, $\rho$ - mass density, cq - specific heat, $T$ temperature, s surface vector, $\mathrm{Sq}$ - source term, $\mathrm{V}$ - control volume, $\delta \mathrm{fb}$ - increment 
of body force, $\mathrm{E}$ - elasticity modulus, $\eta, \lambda$-Lamee coefficients, $\mathrm{K}$ - bulk modulus, $\alpha$ -coefficient of thermal expansion, $\mathrm{t}$ - time, $\mathrm{t}$ '- reduced time, $\tau-$ step time, and $\tau$ 'reduced step time.

Numerical analysis using the finite volume method is based on the approximation of the main equations (1) and (2) by the linear algebraic equations with unknown values of the displacement vector $\mathrm{u}$ and the temperature field $\mathrm{T}$ (Demirdzic et al. 2003). Discretization of time implies subdivision into a certain arbitrary number of time intervals, while spatial discretization refers to the division of the spatial domain into an arbitrary number of finite volumes where the numerical points are located at the center of each volume. For a problem to be mathematically well placed, certain types of initial and boundary conditions must be chosen. The problem is considered well-placed if it has a solution, if it is unique and if it continuously depends on the initial and boundary conditions. As the initial condition at time $t=$ to, the default values of the variable in all points of the solution domain must be:

$$
\phi\left(\mathbf{r}, t_{o}\right)=\phi^{o}(\mathbf{r})
$$

The equation of dynamic equilibrium is of hyperbolic type and at the moment $t=$ to the increment of the displacement (first part in Eq. 6) and the time gradient of the displacement's increment (second part in Eq. 6) must be given at all points of the domain of resolution:

$$
d \mathbf{u}\left(\mathbf{r}, t_{o}\right)=d \mathbf{u}^{o}(\mathbf{r}), \quad \frac{d\left(d \mathbf{u}\left(\mathbf{r}, t_{o}\right)\right)}{d t}=d \dot{\mathbf{u}}^{o}(\mathbf{r}),
$$

The boundary conditions must be specified on all boundary areas of the domain of the solution. They can be Dirichlet's and/or Von-Neumann type, depending on whether the variable boundaries or gradient variables at the boundary of the domain are known. Dirichlet's boundary conditions:

$$
\phi\left(\mathbf{r}, t_{o}\right)=f_{1}(t)
$$

Where is: $\phi=\mathrm{T}, \mathrm{du}$

Neumann's boundary conditions:

$$
\operatorname{grad} \phi\left(\mathbf{r}, t_{o}\right)=f_{2}(t)
$$

\section{Mechanical model}

A suitable way of determining and developing relations of stress and strain relationship in viscoelastic polymers is the use combination of a model of a spring and a dashpot. The most widely used model that describes satisfactorily the viscoelastic properties of materials is a three-parameter model often called the "Standard Linear Body". 


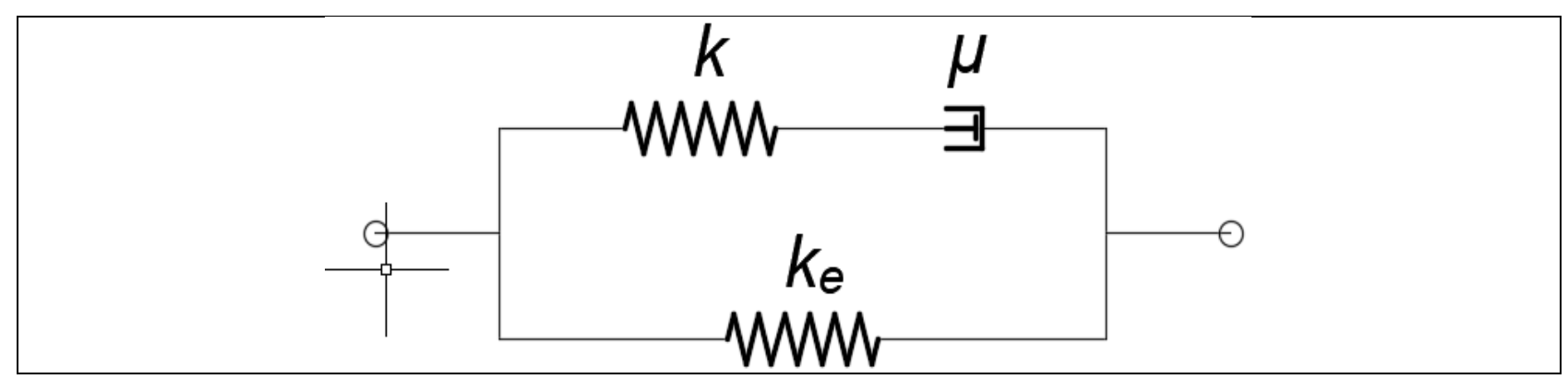

Fig. 4. Model Standard linear body.

The analytical form of this relaxation module is as follows:

$$
E_{\text {rel }}(t)=k_{e}+k \cdot \exp \left(-\frac{t}{\tau}\right)
$$

Where: $\mathrm{k}$ is stiffness of spring, $\mathrm{t}$-time, $\tau$-relaxation time $(\tau=\mu / \mathrm{k})$, and $\mu$-dynamic viscosity. In the case in which there is an experimentally determined value of the relaxation module in tabular and/or graphic form, the task is to determine the analytic form of the relaxation module Erel $(\mathrm{t})$. The most effective and the most common method for approximating this type of results is the method of the smallest squares or its variation.

The method of the least squares is based on the principle that they are the best parameters $a, b$ for which the sum of the squared is the difference between the measured values yi, $(i=1,2, \ldots, n)$ and the calculated values $f(x i, a, b)$ are minimal. Since we have assumed the use of a model of a standard linear body whose analytic form is expressed as:

$$
E(t)=E_{1}+E_{2} e^{-t / \tau}
$$

This problem is reduced to determining the parameters E1, E2, and $\tau$. The difference of the square between the measured values and the budget values could be expressed in the following form:

$$
F\left(E_{1}, E_{2}, \tau\right)=\sum_{i=1}^{n}\left(E\left(t_{i}\right)-E(t)\right)^{2}
$$

Where $\mathrm{n}$ is a number of measurements. Then, from the condition that the stated sum is minimal, there are three local extremes:

$$
\frac{\partial F}{\partial E_{1}}=0, \frac{\partial F}{\partial E_{2}}=0, \frac{\partial F}{\partial \tau}=0
$$

From the last expression, there arise three nonlinear equations with three unknown variables $(E 1, E 2$, and $\tau$ ) whose solution yields an analytic expression for a relaxation module that can be further used in the numerical calculation. 
Obucina, M.; Dzaferovic, E.; Ibrulj, J.; Cekic, A.; Kuzman, K. M.; Kariz, M. \& Ser...

\section{Examples of application}

In the following example, an oscillatory DMA test ("amplitude sweep") with variable load amplitude and a constant frequency value is performed. From such a test, results were obtained for the values of "Storage Modulus" and "Loss Modulus" (Fig. 5 and 6).

From Fig. 5, it is seen that the value of the "Storage Modulus" is quite constant, as is expected since it represents stored energy that can be recovered at any time. In Fig. 6, in contrast to the "Storage modulus", it is seen that the value of the "Loss modulus" is changed, or is offset from one constant value.

The point at which this value begins to deviate from an average value is called "the yield point", and until then the material may be considered to be linearly viscoelastic (Mezger, 2002).

After this area, it is considered that the response is non-linear. The determination of the linear viscoelasticity area (LVE) can be determined by simple visual consideration or by using certain software for analysis. In this paper, research was limited to the linear elasticity region.

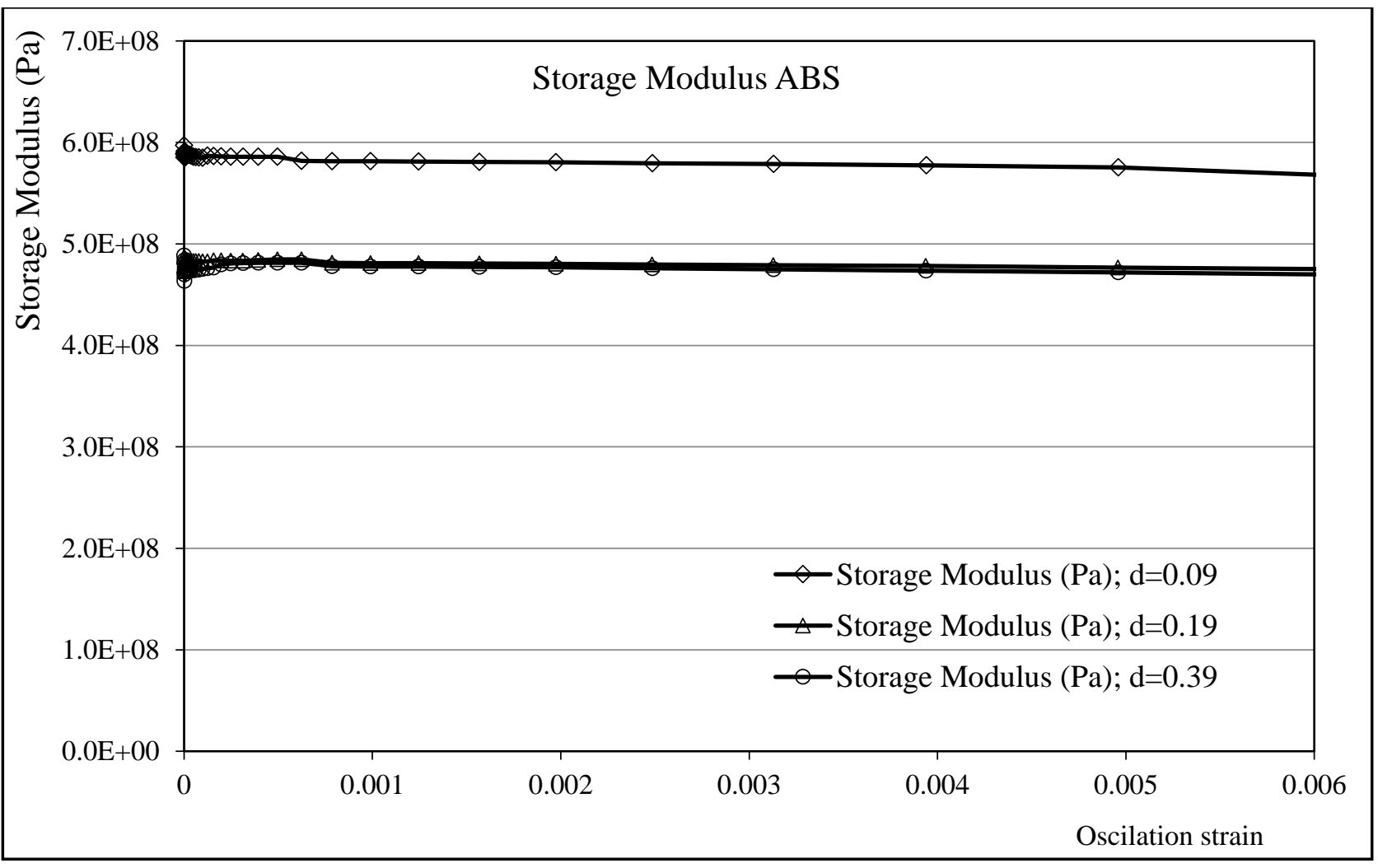

Fig. 5. "Storage Modulus" G' for material ABS depending on printing layer thickness. Presenting values of frequency $\omega=6.28 \mathrm{rad} / \mathrm{s}$, ambient temperature $\mathrm{Tok}=30^{\circ} \mathrm{C}$.

Figure 6 shows that the range of linearity is up to the oscillation strain value 0.006 . 


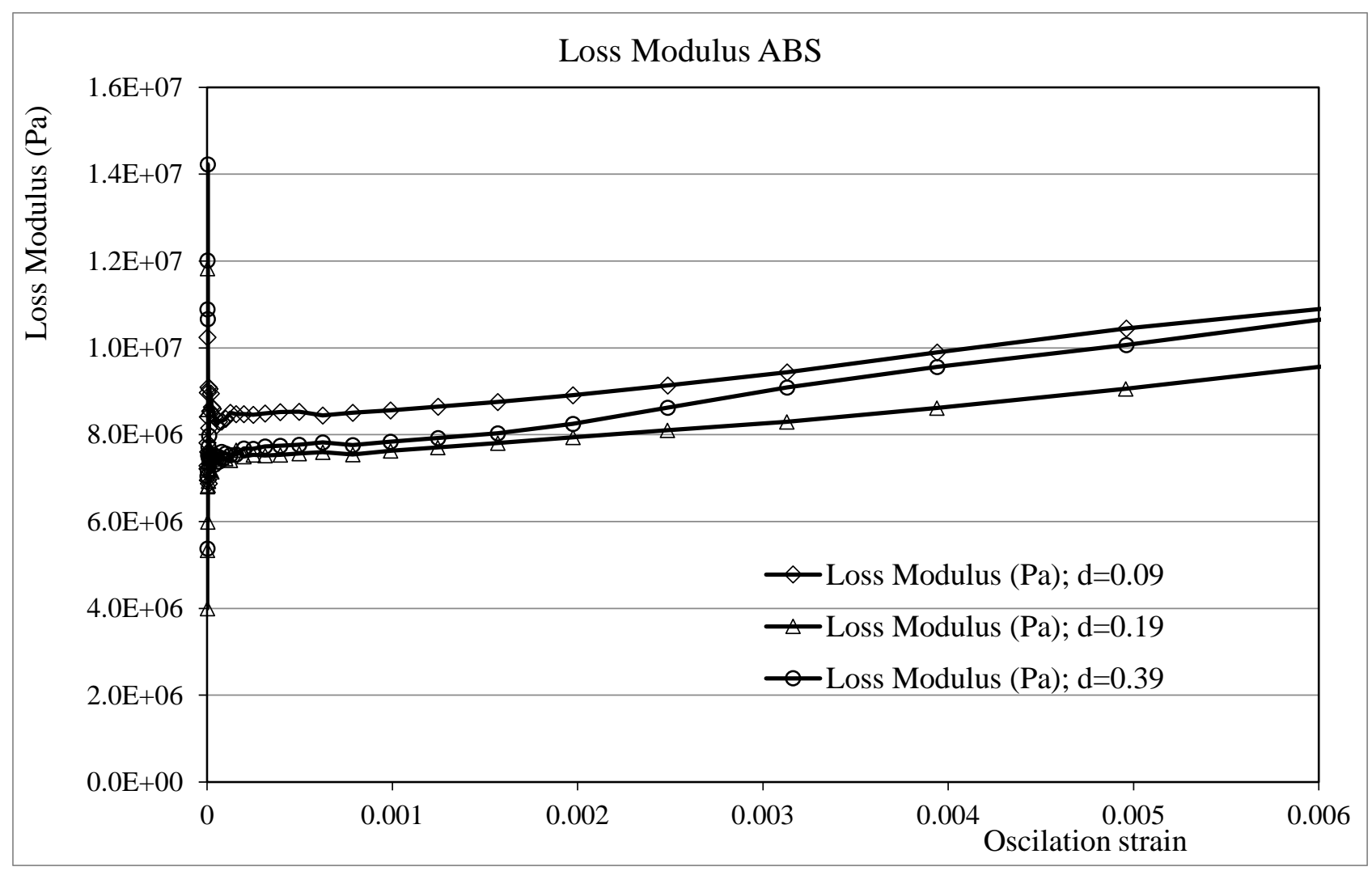

Fig. 6. "Loss Modulus" G” for material ABS depending on printing layer. Preset values of frequency $\omega=6.28 \mathrm{rad} / \mathrm{s}$, ambient temperature $\mathrm{Tok}=30^{\circ} \mathrm{C}$.

From the relationship between the storage module and the loss module, it can be concluded that the material has more solid rigidity $\left(G^{\prime}>G^{\prime}\right.$ ) $)$ or the dominant characteristics of the fluid (G” $>$ G').

With ABS material, there are the dominant characteristics of a solid body since the value of the storage module is greater two decades (102) than the values of loss module.

When the values of both modules are known, then using certain standard mechanical tests and numerical analyses, the results of these two approaches can be compared.

Such an analysis was done in this paper, where the samples were made of ABS material in three layers $(\mathrm{d}=0.09 \mathrm{~mm}, \mathrm{~d}=0.19 \mathrm{~mm}, \mathrm{~d}=0.39 \mathrm{~mm})$ subjected to a simple tensile test.

The sample geometry is simple and suitable for analysis in the $2 \mathrm{D}$ domain while the load is a combination of "ramp" function and constant load (Fig. 7). 


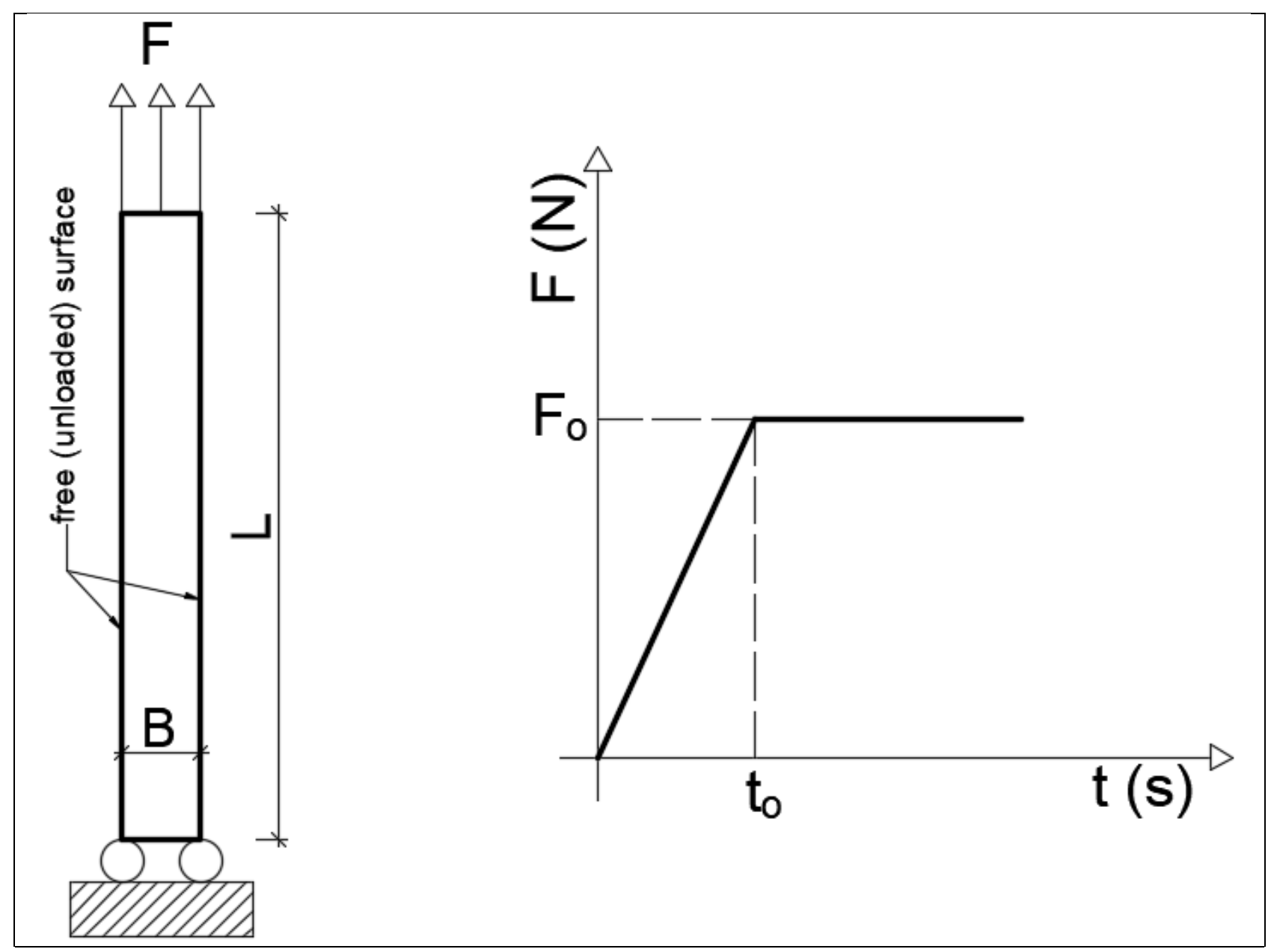

Fig. 7. Geometry and boundary conditions for tensile test. $\mathrm{B}=10 \mathrm{~mm}, \mathrm{~L}=80 \mathrm{~mm}$, $\mathrm{Fo}=300 \mathrm{~N}$.

Depending on the layout of the sample element, a situation occurs in which the numerical and experimental results agree; this is also true in which the layer $d=0.39$ $\mathrm{mm}$, while in other cases the deviation of the results is significant.

This indicates the need for experiments of this type to be performed carefully and precisely, since a slight deviation in experimental results can lead to multiplication and to the incorrect determination of the analytical form of the relaxation function.

It is also visible that the characteristics of the material depend on the printing layer thickness.

Thus, from the last figures $(8,9$, and 10$)$, it can be seen that the deformation is higher, because the value of the layer is larger or rougher than the print form, and this is expected. 


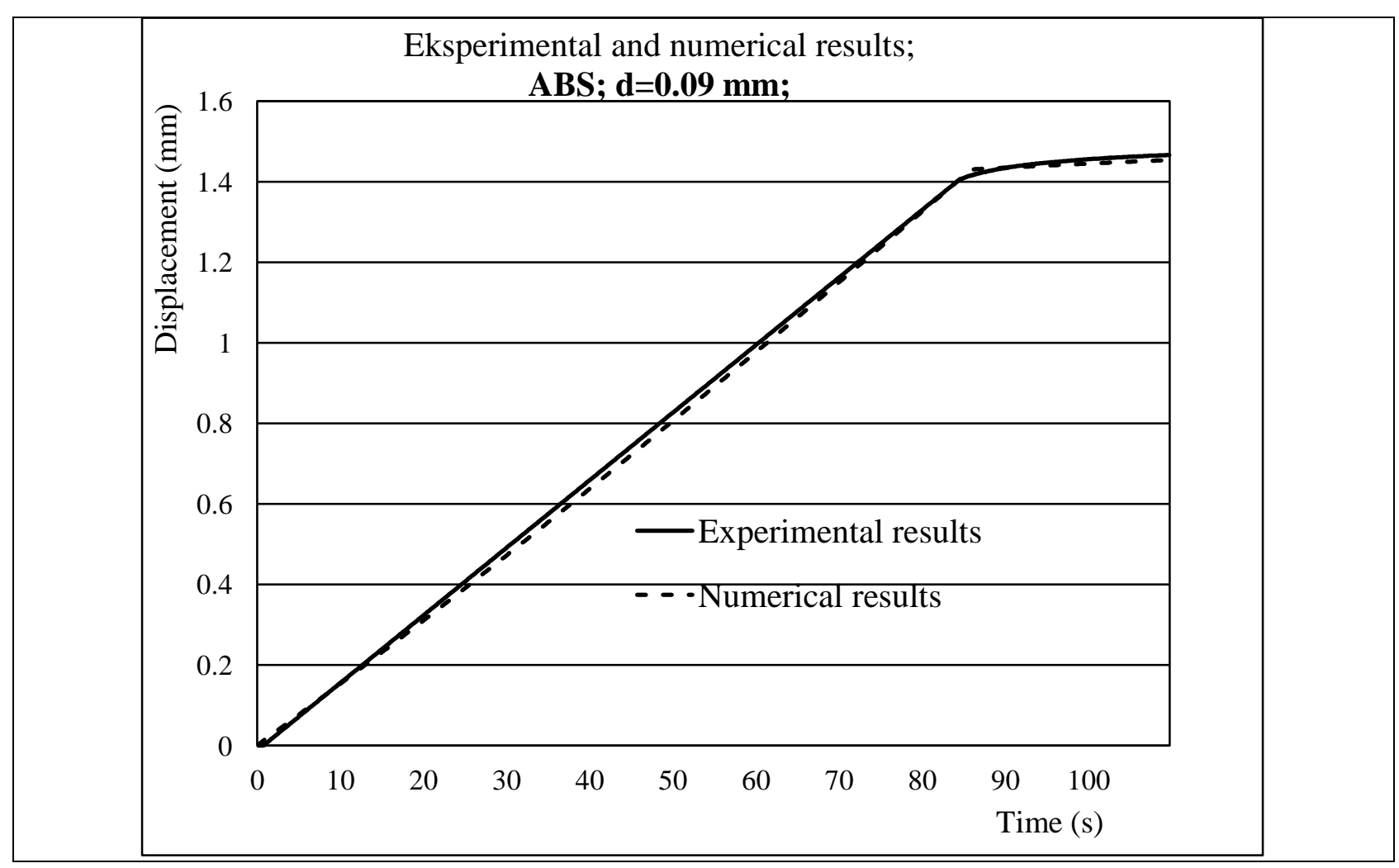

Fig. 8. Numerical and experimental results for sample made of ABS printed with layer thickness $0.09 \mathrm{~mm}$ to $=85 \mathrm{~s}$.

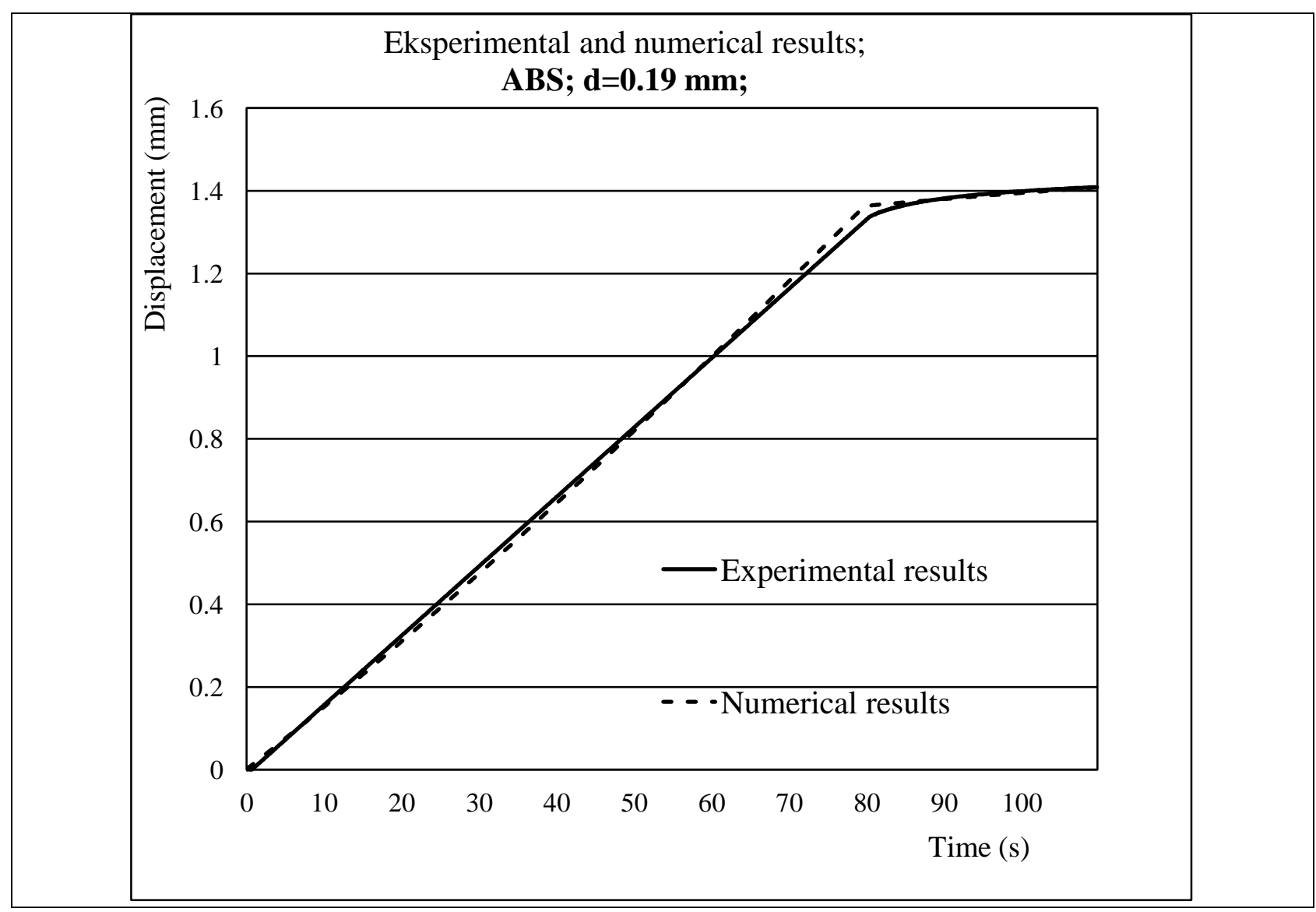

Fig. 9. Numerical and experimental results for sample made of od ABS printed by layer $\mathrm{d}=0.19 \mathrm{~mm}$ to $=81 \mathrm{~s}$. 


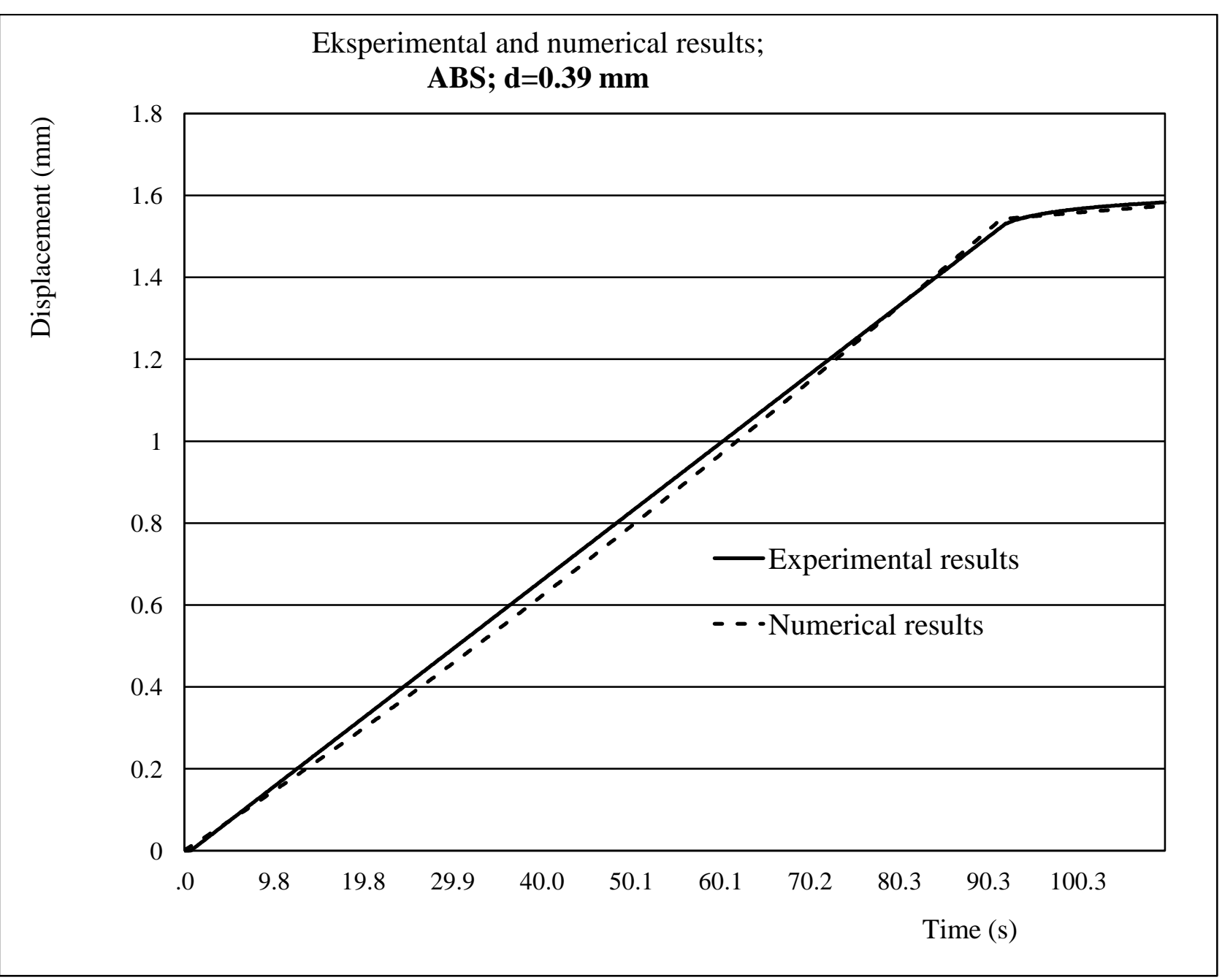

Fig. 10. Numerical and experimental results for sample made of ABS printed by layer $\mathrm{d}=0.39 \mathrm{~mm}$ to $=92 \mathrm{~s}$.

\section{Conclusion}

In this study, one standard form of determining the viscoelastic characteristics of the material is presented, which is primarily the storage modules $\left(\mathrm{G}^{\prime}\right)$ and loss modules (G”) for the particular 3D printing material (ABS). A DMA technique was used to experimentally determine the values of these modules and then proceeded to a simple tensile test that is suitable for numerical analysis.

The numerical analysis used the incremental principle of calculating the stress and deformation of materials. The method of finite volumes is introduced in the discretization of time, space, and equations, while they "memorize" the validity of the same in calculating the deformation and stress in the material at each time step.

The selected examples have shown that the numerical and experimental results are satisfactorily consistent with the higher values of the print layer, while in the "finer" degree of 3D printout the deviations are more significant.

Future research will include an analysis of the thermoviskoelastic properties of polymer materials used in $3 \mathrm{D}$ printing. It will be done upgrading the existing numerical model with the use of relaxation functions in the form of Prony's series. 


\section{Acknowledgements}

The authors acknowledge the financial support of the Slovenian Research Agency within the framework of project BI-BA-JR /2015/47 (Properties of wood materials and adhesives for 3D printing technology) and research program P4-0015.

\section{References}

Arivazhagan, A. \& Masood, S. H. (2012). Dynamic Mechanical Properties of ABS Material Processed by Fused Deposition Modelling, International Journal of Engineering Research and Applications (IJERA), Vol. 2, Issue 3, 2248-9622, DOI: 10.9790, Vol. 2, pp. 2009-2014

Berman, B. (2012). 3-D printing: The new industrial revolution, Business Horizons, 55, DOI: 10.1016/j.bushor.2011.11.003, pp. 155-162

Brown, E., M. (2001). Introduction to thermal analysis: techniques and applications, Springer, USA

Cekic, A.; Obucina, M.; Begic-Hajdarevic D. \&. (2017). Analysis of mechanical properties of alternative materials for process fused deposit modeling, Proceedings of the 28th DAAAM International Symposium, ISBN 978-3-902734-11-2, ISSN 17269679, Katalinic, B. (Ed.), pp. 0253-0257, Published by DAAAM International, Vienna, City, DOI: 10.2507/28th.daaam.proceedings.034

Cekic, A.; Rasovic, N.; Obad, M.; Kaljun, J.; Dolsak, B. \& Begic-Hajdarevic, D. (2016). Production of optimized layered products using intelligent support, Proceedings of the 26th DAAAM International Symposium, ISBN 9783-902734-07-5, ISSN 1726-9679, Katalinic, B. (Ed.), pp. 0271-0279, Published by DAAAM International, Vienna, City, DOI:10.2507/26th.daaam.proceedings.037

Demirdzic, I.; Dzaferovic, E.; \& Ivankovic, A. (2005). Finite-volume approach to thermoviscoelasticity Numerical Heat Transfer, Part B, 47, DOI:10.1080/10407790590901675, pp. 213-237

Demirdzic, I.; Dzaferovic, E. \& Ivankovic, A. (2003). Predicting residual stresses due to solidification in cast plastic plates, 4th International Congress of Croatian Society of Mechanics, Bizovac, Croatia, pp. 71-73

Dzaferovic, E.; Ivankovic, A. \& Demirdzic, I. (2000). Finite Volume Modelling of Linear Viscoelastic Deformation, 3rd International Congress of Croatian Society of Mechanics, Cavtat, Croatia, pp. 245-253

Kariz, M. (2011). Vpliv termicne modifikacije lesa na utrjevanje lepil in kakovost lepilnih spojev, Doctoral thesis. Ljubljana, Univ. v Ljubljani, Biotehniška fakulteta.

Menard, K. P. (1999). Dynamic mechanical analysis a practical introduction, CRC Press, USA

Mezger, T. G. (2002). The Rheology Handbook, Vincentz Verlag, Hannover, Germany 
Obucina, M.; Dzaferovic, E.; Ibrulj, J.; Cekic, A.; Kuzman, K. M.; Kariz, M. \& Ser... Mohamed, Omar A.; Masood, Syed H. \& Bhowmik Jahar L. (2016). Investigation of dynamic elastic deformation of parts processed by fused deposition modeling additive manufacturing. Advances in Production Engineering \& Management, 11, 3, (227-238), ISSN: $1854-6250$

Wimmer, R.; Steyrer, B.; Woes, J.; Koddenberg, T. \& Mundigler, N. (2015). 3D printing and wood, Pro Ligno, Vol. 11, 2069-7430, pp. 144-149 